\title{
Tempo Histórico e Cronologia: o conhecido e o ensinado por professoras dos anos iniciais.
}

Magda Madalena TUMA ${ }^{1}$

\section{RESUMO}

Expressando a pluralidade do tempo histórico o contexto sociocultural de sua construção e sendo a cronologia também representativa de seu tempo e espaço, intentamos neste estudo, o reconhecimento de pressupostos de mudanças recentes na historiografia, especificamente na cronologia, em discursos e ações pedagógicas de quatro (4) professoras da quarta (4ª) série do ensino fundamental. As alternativas buscadas pelas professoras para este ensino foram analisadas, tendo em vista a repercussão da formação docente sobre estas opções e explicações para o ensino de História. Tendo como referencial os pressupostos teóricos advindos do movimento dos "Les Annales", a pesquisa foi realizada por meio de duas entrevistas semidiretivas, observação do espaço escolar e das aulas das professoras, além da coleta e análise de livros didáticos, cadernos dos alunos, currículo escolar e programas de disciplinas do curso superior de História. Figuram dentre os referenciais teóricos utilizados para este estudo as contribuições de Piaget, Vygotsky, M. Bloch, L. Febvre, Furet; Certeau, Le Goff, Nora, Rüsen e Kosseleck.

Palavras-chave: Ensino de História - Formação de professores - Tempo histórico - Cronologia.

Sendo a forma de controle temporal representativo de construção histórica e sociocultural das sociedades, esta se constitui como expressão de seu próprio tempo e espaço. A sociedade ocidental vive momento, no qual, a aceleração do tempo ésentida na opressão do movimento cotidiano que é regido pelo tempo métrico, cronológico. Esta referência temporal se consolidou no processo de mudanças ocasionadas pela intensificação da urbanização e industrialização ocorrida a partir do século XVIII.

' Docente de Ilidática do Ensino de História e Geografia do curso de Pedagogia e do Programa de Pós-Graduação em liducação Escolar do Departamento de Educação da Universidade Estadual de Londrina. Doutora em Educação pela Universidade Estadual de Campinas-UNICAMP. 
Na sociedade ocidental temos na tradição jułlaico-cristã os fundamentos desta concepção temporal e no advento do cristianismo o seu fortalecimento como tempo unificado e pensado de forma ascendente. Na convivência com outras construções temporais esta concepção mantém vitalidade suficiente para a permanência como continuum temporal compartimentado por métricas convencionadas que trazem a homogeneização externa sem eliminar a multiplicidade do valor subjetivo do tempo que permanece com o sujeito social. Esta condição de abarcar compreensões que não se circunscrevem ao visível e simultaneamente tantas concepções quantos somos o que inclui as diferenças trazidas pelo ritmo e valor dado pelas sociedades às opressões temporais, pode ser entendido como um dos elementos de manutenção de sua presença. Sendo múltiplos os significados que permanecem como intrigantes temos questão complexa que por sua amplitude não será o objetivo deste estudo, onde estabelecemos como recorte o entendimento da concepção temporal de professoras que atuam nos anos iniciais do Ensino Fundamental no que se refere à cronologia.

A cronologia para a História permanece como necessária em datações, periodizações, ciclos, datas-limite, utilizando variados instrumentos de mensuração como calendários e outros, mas não de forma acomodada e sim gerando movimentos para mudanças no que se refere à homogeneização trazida pelo tempo linear e evolutivo. (0 que se pretende é a desnaturalização de tal concepção com a inserção das descontinuidades temporais, da simultaneidade, da heterogeneidade, das múltiplas durações, enfim, da multiplicidade que corrobora a cronologia como construção sociocultural e histórica, portanto, plural.

Este intento não exclui a natureza como parte das elaborações das sociedades, pois este processo conforme Elias (1998, p.68), foi difícil e complexo para que as sociedades conseguissem "se orientar melhor em seu universo. Eles conseguiram substituir os movimentos do Sol, da Lua e dos outros astros - referenciais cronológicos e instrumentos de sincronização relativamente irregulares - por uma rede cada vez mais densa e regular de 'cronômetros' artificiais".

Os instrumentos de controle temporal, paulatinamente, se tornaram imperativos na organização da prática humana e, paralelamente, passam a dominar como ente abstrato ao não se expor a dimensão do processo variado de sua construção histórica e sociocultural. É o 'tempo concreto, metrificado e naturalizado' que é afirmado na omissão de sua historicidade, aquele que tem 
sido transformado em memória nacional, por meio de sistema métrico materializado em calendários, relógios, cronômetros e outros instrumentos que norteiam a organização do cotidiano e dos calendários políticos.

A omissão da historicidade desta temporalidade ao vigorar na mídia como nos trabalhos pedagógicos, conteúdos e práticas escolares das séries iniciais e subsequientes, corroboram a hegemonia da cronologia na perspectiva tradicional, sendo esta, muitas vezes, confundida com a própria História, o tempo histórico e o tempo físico. Somado este contexto ao ambiente familiar e sociocultural, tem-se conjunto que mantém na contemporaneidade a concepção da trama temporal em orientação determinada, metrificada e linear.

A história tradicional ao se apropriar dos sentidos desta cronologia constituiu pressupostos para a produção historiográfica que extrapolaram para o âmbito do ensino e a aprendizagem de História. Esta condição potencializou a eficácia da cronologia linear e ascendente, como forma de agir e pensar, e constituiu-se como mais um empecilho para mudanças na compreensão do tempo histórico. Adquirindo status de "força contextual" repercute efetivamente sobre a "prefiguração" do contexto sociocultural.

$\Lambda$ noção de 'contexto' neste estudo tem o sentido trazido pelo construcionismo social, o que para Pearce (1996) não permite atribuir à "força contextual" o pleno domínio, pois é visível que as mudanças não deixam de acontecer. 0 movimento de que insere a "força implicativa" é aquele que se expressa em ações de sujeitos sociais que provocam ou não mudanças na prefiguração do contexto.

Esta argumentação nos leva a atribuir aos pressupostos do tempo histórico dos Les Annales a condição de "força implicativa" por gerar 'estranhamentos' ao agir sobre a "força contextual" do ambiente sociocultural onde predomina o entendimento da História e da cronologia de forma tradicional, possibilitando ações para mudanças, assim como de resistência a elas, tanto para a cronologia em narrativas da produção historiográfica, quanto para o ensino de História e concepçoes temporais na contemporaneidade.

Como sujeitos que elaboram conhecimentos e os disseminam os professores no processo de formação das pessoas, têm a condição de 'força implicativa' para a mudança ou não, o que torna pertinente o reconhecimento dos conhecimentos que elaboram. Assim, será o conhecimento expressado por quatro professoras da $4^{a}$ série (atual $5^{\circ}$ ano) do ensino fundamental por meio do discurso que elaboram 
sobre o tempo histórico, no que se refere à cronologia, o que nos possibilitará apontamentos sobre repercussões para o ensino de História.

Considerando o conhecimento construído pelas professoras, como resultado de embates permeados por estratégias de resistência e adesão, que emergem por meio de representações sociais, que como categoria mental, para Chartier (1990), resulta de compartilhamentos e construções singulares, conformadas à realidade social de onde falam, entrevistamos as quatro professoras em duas oportunidades. Na primeira, que será o objeto desta análise, focamos a concepção de História, ensino e tempo histórico. Na segunda entrevista, a trajetória de vida foi abordada em variadas dimensões, para a composição tanto da opção profissional quanto da construção do conhecimento sobre o tempo histórico. Entendendo os conhecimentos construídos pelas professoras como 'outra produção', foram estes analisados na confrontação com os pressupostos teóricos gerado pelo movimento de historiadores iniciado em 1929, na França, e denominado Les Annales.

A observação das aulas e ambiente escolar; a análise de atividades dos cadernos dos alunos e os livros didáticos formaram os demais elementos do conjunto analisado para este estudo, que é parte de pesquisa mais ampla realizada para a tese de doutoramento ${ }^{2}$. O espaço de realização foi uma escola pública municipal, criada em 1980, na região norte do município de Londrina, Paraná, que com 718 alunos, oferta em três turnos o ensino fundamental (séries iniciais) e a Educação de Jovens e Adultos. A segunda escola éprivada e iniciou suas atividades na década de 70 com curso preparatório para vestibulares. Atualmente atende em torno de 2000 alunos distribuídos pela Educação Infantil, Ensino Fundamental e Ensino Médio. Este colégio está situado na região sul do município.

\section{Elaborações de professoras sobre o tempo histórico e a cronologia}

Os conhecimentos são dinâmicos e circulam pela sociedade como elaborações e produtos representativos de múltiplas interações sociais no decorrer da vida das pessoas, o que torna 'falso problema' conforme Chartier (1990), tentar

\footnotetext{
'Tese de doutoramento defendida em 2005 na Universidade Estadual de Campinas - UNICAMP sob a orientação da IRR(F". I)Ra . Einesta Zamboni intitulada "Trajetórias e singularidades de professoras das séries iniciais: conhecimentos solbre o tempo histórico".
} 
situá-los de forma dicotomizada através de classificações como erudito e popular; científico e do senso comum. Estas oposições que confrontam a diversidade de perspectivas não se sustentam perante a elaboração dos conhecimentos que provém de variadas circunstâncias que se interpenetram, se relacionam, sendo reelaborados na prática e nas relações sociais, o que leva à heterogeneidade, à multiplicidade e também às permanências.

() conhecimento das professoras quando referido neste estudo está no sentido de que temos o conhecimento como construção que Lahire (2002) coloca como 'domínio da realidade' por força do qual, estruturas mental e material, são objetivadas na linguagem, assim como nas ações e opções do sujeito, situadas no contexto das interações sociais.

Apontamentos relacionados aos pressupostos produzidos pelos Les Annales, se inserem nesse processo, para o apontamento das diferenças e semelhanças entre o que foi preconizado para ser interiorizado nos espaços de ensino, e será a contraposição com as noções da historiografia tradicional o que dará visibilidade às mudanças ou não, na passagem de um sistema de representações para outro, assim como, dos bloqueios, hesitações, enfrentamentos, adesões, contradições que permeiam o processo.

Ártemis ${ }^{3}$, que trabalha na escola pública desde 1989, é graduada em Geografia. Sobre a História comenta que não grava nome de autores e, em relação ao processo de construção de conhecimentos pela criança, lembra de Piaget e Emilia Ferreiro como aqueles que deram embasamento sobre o tempo "mas é o tempo assim mais, é emocional, não é o tempo histórico em relação à História" (Apêndice B, v. 2, p.333) .

Em sala de aula trabalha com documentos de acordo com a proposição feita por Dafne (professora da escola graduada em História), ao considerar que esta tem conhecimentos "por ser uma historiadora, ela, lógico! Ela parte do princípio documentário. Documental" (Apêndice B, v. 2, p.336). Na interpretação do texto documental em sala de aula explora o objetivo do documento; a datação; 0 vocabulário; as mudanças na ortografia e sua forma de elaboração e encaminha para trabalhos com a linha do tempo, construção da seqüência cronológica e comparações entre o documento da criança e o de outro tempo.

\footnotetext{
- Os nomes das professoras utilizados neste estudo são fictícios e foram atribuídos com base em algumas características das mesmas que a autora relacionou a personagem de mitos literários.

* Acesso às entrevistas e documentos que compõem os apêndices - Biblioteca da FE/UNICAMP.
} 
Questionada sobre a pertinência do uso do documento e da linha de tempo para a construção do conhecimento histórico e compreensão da cronologia, ela responde que associa o uso do "documento ao processo e a linha do tempo à cronologia" (Apêndice B, v. 2, p.338). Perante a hesitação que expressa, pergunto se dá para separar e ela explica: "Não, de jeito nenhum [...]. Eu acho impossível você separar o tempo do fato que está acontecendo" (Apêndice B, v. 2, p.338).

Ártemis entende a cronologia e o acontecimento como elementos quase que absolutos para a constituição da História e isso se evidencia ao explicar a atividade sobre a linha do tempo (Apêndice F, v. 2, p.602, 603 - 605), quando indica que:

a cronologia seriam as datas, as datas que eles levantaram. Tipo mil novecentos e noventa, mil novecentos e noventa e um, mil novecentos e noventa e dois, uma sequiência. E ao fato histórico dele, porque é em cima da cronologia é que ele vai construindo a História (Apêndice B, v. 2, p.337).

Para a operação histórica ela "inter-relacionaria" tempo e História. Na continuidade explica que "Às vezes, você pode pegar o 'a' e o 'b' e relacionar. Agora, inter-relacionar é uma ação entre os dois, então, é por isso que eu acho que não dá para você trabalhar só o cronológico" (Apêndice B, v. 2, p.339).

Este posicionamento nos levou a acreditar que havia superado o entendimento da cronologia como trajetória linear à qual a História deve subordinar-se pela orientação dada pelos acontecimentos. Será? Refaço então a pergunta sobre cronologia e compreensão do processo histórico, indagando se a ausência da cronologia compromete a compreensão do processo histórico, ao que ela responde: "se vocênão fizer o fator cronológico, você não vai entender o que aconteceu e você pode não pensar no que vai acontecer". Reafirmando a presença da cronologia como importante afirma sua necessidade para o entendimento "do passar do tempo, no sentido de passar, assim tipo: o que aconteceu? Quais foram os fatos que levaram a estar como está hoje?" (Apêndice B, v. 2, p.340).

Demonstrando em suas reflexões sobre o tempo que conhece abordagens diferentes e também próximas àquela que expressa; titubeia em alguns momentos em relação à sua própria reflexão. Mas, é seu enfoque o que prevalece ao expor seu pensamento da seguinte forma: 
se eu não tivesse feito Geografia ou não tivesse entrado na universidade e pego esse ramo do estudo, eu poderia, assim falar, que dá para estudar o fato sem estar ligado ao tempo cronológico, mas pela minha concepção, pelo que eu já estudei, do que eu já sei, do que eu já analisei; eu acho que não dá para separar os dois. knt: Processo histórico e cronologia? História e cronologia?

Ártemis: Não dá para separar, mas se eu não tivesse ido até a universidade, se eu tivesse ficado só com a Secretaria de Educação. Não! Na Secretaria eu já poderia até ter essa diferença. Mas, se eu tivesse ficado só com o Magistério, não faria isto (Apêndice B, v. 2, p.341).

$\Lambda$ formação universitária é colocada como diferencial em relação ao senso comum, assim como o ambiente do exercício profissional contém a possibilidade de construção de saberes. Mas a transformação histórica e a compreensão do processo permanecem vinculadas à cronologia mantida como conhecimento que pode ser compreendido pelas crianças por meio de atividades como a linha de tempo, pois a:

linha do tempo, é análise do tempo passado, do tempo presente e uma previsão do futuro, entendeu? Você vai fazer um paralelo entre os três, por exemplo: quando nós estudamos na época lá, do descobrimento do Brasil em abril, nós fizemos o Brasil hoje, o Brasil ontem e o Brasil amanhã, então o ontem foi modificado (Apêndice B, v. 2, p.339).

Ártemis não tem receio em apresentar suas dúvidas e nem suas próprias elaborações, pois valoriza seus conhecimentos e tem necessidade de não se omitir perante o 'outro', mesmo nas diferenças. 0 ambiente profissional é ambiente de desafios que a coloca em constante busca na tentativa de responder às necessidades imediatas. A cronologia é importante, mas o que chama atenção é a subjetividade que atribui ao tempo e, nele, a consideração da pluralidade cultural e temporal.

Micaela que atua em escola pública e privada, paralelamente, é graduada em Administração e gosta da disciplina História porque "história eu acho muito, muito legal, pra gente entender o hoje” (v. 2, Apêndice B, p. 464). Em relação à questão do tempo, explica que: 
Tempo! Nossa! [...] ainda agora a gente estava falando de um texto, agora, que falava de tempo, o tempo passou na conversa. Tempo é estranho, é difícil definir a palavra tempo. Tempo para mim está ligado com acontecimentos, né? 0 tempo, a gente fala 'o tempo vai passando, as coisas vão acontecendo'. Então, tempo para mim está relacionado a acontecimentos, é lógico que isso assim é muito voltado para História, mas se fosse pegando o sentido cronológico mesmo,... (Apêndice B, v. 2, p. 465).

O estranhamento de Micaela nos remete a pensamento que parece remeter o tempo a fluxo contínuo orientado para o futuro e seu vazio preenchido por 'acontecimentos' que dão visibilidade e que conformam a História. Também demonstra que não considera como intrínsecas as relações entre o tempo e a História e, sim, entre cronologia e o tempo. Ao explicar como o tempo está relacionado à História ela diz que:

Eu estou pensando que quando a gente fala, para mim tempo, me lembra acontecimento. Daí a gente volta àquela coisa de estar voltando, fala 'voltando no tempo', está retrocedendo para chegar até agora. Então tempo, eu não saberia assim definir: bom, tempo é isso, sabe? Eu não teria... tempo pra mim é uma coisa muito relativa, né? [...] Então eu ficaria te devendo essa definição de tempo, o que é tempo necessariamente (Apêndice B, v. 2, p.465).

Ignorando a pergunta em relação à História se atém ao tempo, reafirmando-o como subjetivo e concretizado pelos acontecimentos que permitem a percepção do movimento de volta ao que era, ao passado, a partir de sua posição no presente para o recolhimento dos acontecimentos sucessivos. Como professora trabalha o tempo histórico com as crianças com a

linha do tempo. Ia começar lá, desde o tempo que ela está lá, que ela foi gerada na barriquinha até hoje. Entendeu? [...] vou trabalhar o tempo histórico dela. Para mim, se hoje me perguntasse eu falaria isso: História de vida seria acontecimento, tempo histórico, seria acontecimento de vida, evolução(Apêndice B, v. 2, p.466).

Expressando a aceitação da concepção e organização temporal atual como 
natural e não como construção cultural e histórica em diversidade social, neste momento, Micaela compõe com as demais professoras que também utilizam a linha do tempo e com as quais dialogamos, a expressão do formato da cronologia ocidental ensinado como tempo concreto e natural, com a omissão da historicidade e ênfase na ordenação linear materializada pela cronologia. 0 ensino da História é vivenciado pelas crianças na organização de 'acontecimentos' confundidos com 'fatos históricos', e orientados em seqüência temporal linear e ascendente, o mesmo acontecendo com o trabalho com a história de vida da criança, que terá, em seu desdobramento, a elaboração da linha do tempo.

O complicador está na omissão das contradições, das rupturas que ficam em segundo plano e a omissão da multiplicidade de tempos com os quais convivemos para o reconhecimento pelas crianças. Há ausência de problematização e preponderância do tempo linear que coloca em segundo plano o tempo cíclico, o tempo da memória e o tempo presente como portador de outros tempos (PELBART, 2004).

Para Micaela, os acontecimentos que compõem o tempo histórico são fragmentados e, para terem inteligibilidade, necessitam ser colocados na ordenação temporal, sendo esta compatível com os objetivos do próprio livro didático que utiliza (vide v. 2, Apêndice D, p. 560) e que propõe o ensino do conhecimento histórico fragmentado em eventos inseridos em linha temporal ascendente. A datação é entendida como necessária à compreensão do processo histórico

gosto de datas, viu! [...] Eu acho legal, eu acho importante. Não cobro como falei assim em prova. Eu não peço alguma resposta que seja: quando...? [...] pedir uma questão: 'que dia foi tal coisa?' Não! A não ser acontecimento assim que nem a Proclamação da República, que teve o ano de 1879 e tal (Apêndice B, v. 2, p. 474).

Para a organização do raciocínio histórico a datação é reafirmada como necessária, para "localizar o tempo na História, facilita a compreensão, então você fica: e tal coisa aconteceu antes ou depois? Então se você tem uma data, você já se localiza melhor" (Apêndice B, v. 2, p.472), além de que a transformação da sociedade precisa ser compreendida e, para tal, o "processo histórico, [...] está relacionado a acontecimentos, à evolução dos acontecimentos e a gente precisa desse tempo cronológico, dessas datas, pra gente poder compreender melhor o tempo histórico, eu acho" (Apêndice B, v. 2, p.473).

Ártemis e Micaela não são graduadas em história e construíram muito do 
que sabem no ambiente profissional demonstrando em muitas de suas falas e opções didáticas que as observações do cotidiano de professora respaldam elaborações entre o conhecido na vivência de suas experiências e o novo trazido pelo ambiente profissional.

É necessário ressaltar que não entendemos a cronologia como prejuízo para a criança em seu processo cognitivo de construção da noção de tempo, mas, sim, que a escola pode participar de forma mais intensa e mais crítica nesse processo para que compreendam e exercitem elaborações temporais que se diferenciem da perspectiva tradicional na consideração da relação entre os múltiplos tempos, suas durações, mudanças, contradições e rupturas, contribuindo para ação pedagógica que adquira a dimensão de força implicativa que propicie mudanças na concepção de tempo histórico e, consequentemente, para a compreensão do processo histórico.

Para Dafne que é colega de Ártemis na escola pública a História é:

"vivência mesmo da gente. A participação da gente como cidadã, dentro de uma sociedade e poder exercer isso dentro de uma escola. Poder mostrar que a História, ela não é uma coisa acadêmica simplesmente, é uma coisa que você tá vivenciando, você está vendo, faz parte da tua vida, do seu dia-a-dia, das coisas que você faz, e isso tem uma consequiência, né? Que é o que eu tento pelo menos assim, é... é... colocar no meu dia a dia" (Apêndice B, v. 2, p. 379).

Sendo licenciada em História, atribui ao passado como 'construtor de consequiências' a fonte de recompensas ou punições e o referendum de realidades que seriam previsíveis na racionalidade. Implicitamente, incita a volta ao passado como fonte de orientação do presente, vinculando este à futura realidade que será "consequiência da tua atitude, do hoje, né? E aí, amanhã você vai poder entender qual o porquê desta sua atitude" (Apêndice B, v. 2, p.379).

O tempo histórico está inserido no processo de construção humana, portanto, é compreendido também como tempo cultural, contendo a delimitação temporal dada pela cronologia que serve para "você poder estar realmente por dentro. Saber onde você está. Podendo se localizar em que tempo histórico, em que época tal coisa aconteceu" ( Apêndice B, v.2, p.379). Tentando se distanciar da cronologia, sem prescindir do retorno ao passado, que lhe possibilitará "fazer 
essa regressão, essa busca” enfatiza que tal ação "não estará dependente da [...] data, né?" (Apêndice B, v. 2, p.379).

Na relação que estabelece entre a cronologia e o presente, passado e futuro, a primeira é dispensável para a compreensão da transformação histórica o que afirma com base em observações de vivências em sala de aula quando ao trabalhar a colonização portuguesa percebeu este entendimento quando: "eles [as crianças] colocaram que os 'portugueses pegaram o nosso dinheiro, mas isso não mudou não, professora. Porque o Belinati 5 também pegou o nosso dinheiro,' né?? " (Apêndice B, v. 2, p.393).

Este exemplo é inserido por Dafne para exemplificação da compreensão pelas crianças da dinâmica histórica e sem a presença da cronologia o que pode nos induzir à crença de que negligencia saberes como os marcos temporais métricos que resultam das convenções temporais construídas pela sociedade ocidental. Mas, em seguida, ao comentar atividade para a elaboração da linha de tempo utilizando mapa, nos indica que tal possibilidade se distancia de sua prática (v. 2, Apêndice F, p.614-615), a explicar que: "trabalhei esta data porque estava assim no mapa. Eu achei interessante [...] porque mostrava a busca, saindo de Portugal e as expedições, [...]? É para eles terem noção de que foi uma bem perto da outra, não é?" (Apêndice B, v. 2, p. 390).

Para ela, a cronologia assim utilizada adquire importância para o ensino de História, mas sua restrição permanece extrapolando para as exigências da sociedade que exige tudo muito datado, [...], você tem que ter dia, mês, ano. É importante, mas tem certas coisas que você não precisa, porque o ser humano não guarda tudo assim tudo certinho, assim dia, mês e ano (Apêndice B, v. 2, p.58). Ressaltando a periodização como opção a esta cronologia miúda da escola que exige tal dia de tal ano' como conhecimento histórico, explica que em sua prática considera que

o fato histórico aconteceu, aconteceu em queépoca, né? É século, década, mas não tem aquela coisa, assim, de que a gente passa muito, não... na escola eu vejo muito isso: 'tal dia de tal ano' [...] Esse tempo é [...] para mostrar a grande quantidade de tempo que isso aconteceu, mas não datar esse tempo, sabe?" (Apêndice B, v. 2, p.379).

Belinati é político que foi prefeito do Município de Londrina por três vezes, sendo cassado em sua última gestão no ano de 2000, ano da realização da primeira entrevista. 
O que constatamos é que a restrição da cronologia para Dafne está mais em seu discurso do que na utilização em seu trabalho pedagógico, pois nos cadernos dos alunos as atividades como a linha do tempo e o cálculo em séculos (Apêndice F, v. 2, p.614-615), estão presentes, bem como em conteúdo relacionado às transformações do séc. XIX, quando trabalha com periodização, e onde, novamente, pede a organização em linha do tempo (v. 2, Apêndice F, p.613).

Trabalhando com datação, periodização, com longas e breves durações, o que incomoda Dafne, são os critérios da utilização da cronologia de forma linear. Há nela incômodo com a opressão da cronologia (em sua infância a disciplina temporal foi marcante) o que contribui para seus movimentos de contestação e de busca de alternativas para mudanças.

Tendo a afirmar que Dafne assimilou mais as críticas das Ciências Sociais à forma de abordagem e utilização do tempo na História tradicional notadamente Lévy-Strauss (1989) do que as mudanças introduzidas pelos Les Annales, em relação à cronologia, o que corrobora ao dizer que é influenciada por "um monte de coisas, não só da área de História, mas uso da Antropologia porque a gente trabalha muito com a questão, assim, do tempo" ( Apêndice B, v. 2, p.424).

A Antropologia, certamente, trouxe contribuições para a História em relação à cronologia, o que leva Certeau (1977) a considerar que ela:

"insinua na História uma outra relação com o tempo: já não se trata de um tempo voluntarista, progressista e nítido, que continua sempre a avançar apesar das resistências, mas sim de um tempo que se repete, que evolui em espiral, que tem nós e volta atrás, um tempo manhoso cheio de sinuosidade" (p. 28).

Claude Lévi-Strauss como referência citada por Dafne, elaborou duras críticas à utilização da cronologia pelos historiadores, à qual denominou como código de análise. Para ele esta codificação cronológica, ao conceber as datas em ordenação linear, dissimula a complexidade dos intervalos na mensuração da duração o que o levou a considerar que o código do historiador não se constitui pelas datas e, sim, por classes de datas onde Cada classe se define por uma freqüência e pertence ao que se poderia chamar um corpo ou um domínio da História. Portanto, o conhecimento histórico opera da mesma maneira que um aparelho de frequiência (LÉVI STRAUSS, 1989, p.288). 
Essas críticas foram importantes para a História e auxiliou na colocação do tempo em sua visibilidade métrica como construção cultural, escancarando, conforme Reis (1994b), a dimensão simbólica, heterogênea, descontínua e não linear do 'próprio existir' do ser humano.

Em relação ao Annales, Fernand Braudel é a referência em sua crítica à cronologia, mas Dafne fixa-se nas múltiplas durações, o que coloca como exemplo de possibilidade para a compreensão histórica que prescinde da datação.

Apesar das restrições que faz à cronologia, entende que:

essa cronologia que você fala, essa coisa datadinha mesmo, né? [...] elaénecessária em determinados momentos, para que a criança tenha essa noção mesmo, do tempo cronológico. Ela é necessária, mas eu acho que você não precisa estar o tempo todo em cima dessa cronologia, porque ela consegue entender essa mudança, essa transformação (Apêndice B, v. 2, p.392).

Atribuindo à pesquisadora uma conceituação ou valoração do tempo cronológico que não foi expressa, reafirma suas restrições à métrica temporal, ressaltando que em sua ação docente que entende a cronologia como parte necessária à compreensão do processo histórico, mas em uso restrito, pois desconsidera a cronologia na História como auxiliar para a estimativa de durações, da velocidade das mudanças e para a identificação de marcos referenciais. A cronologia, mesmo criticada, faz parte dos trabalhos pedagógicos e, em sua metodologia, tem tido sucesso pelas demonstrações de compreensão da noção de sucessão, duração assim como de periodização pelos alunos o que, para ela, dão fundamentos para a percepção da longa e média duração no processo histórico.

Antígona, licenciada em História, que no período da pesquisa completaria 25 anos de magistério em escola privada, relata que entende a História como "fatos que aconteceram e foram feitos pelo próprio homem. Então, História não tem como tirar $[. .$.$] de dentro da minha vida. Eu acho que a História está no passado,$ ela está hoje e sempre preparando o indivíduo, a pessoa para mudança, para 0 futuro. [...]" (Apêndice B, v.2, p.425).

Demonstrando o reconhecimento da continuidade histórica, o passado para ela não é repositório de erros, pois nele busca evidências para legitimar o que é direcionado para o futuro e mantém a História como mestra da vida. Ela tem no 
conhecimento histórico produzido a sua fonte da verdade, mesmo considerando que foi o dia-a-dia da ação docente que the trouxe muito mais que o curso universitário pois "quando eu fiz História, [..] Há quanto tempo! Setenta e cinco [...]. eles colocavam o tempo como aquilo que te falei no princípio, uma coisa muito decorativa: decoreba, copereba; [...]. (Apêndice B, v. 2, p.431).

Nessa crítica à sua formação universitária e na exaltação ao seu próprio esforço na construção de seus saberes sobre a História expressa a luta do indivíduo que busca superar empecilhos colocados à realização do desejo de marcar sua individualidade, e não reconhece o que para Elias (1994) provém da própria estrutura das experiências sociais e entende sua consciência histórica como construída em sua orientação da vida prática, portanto, como vivida na 'intencionalidade do agir humano' (RÏSEN, 2001, p. 79).

() 'tempo' pode ser o tempo físico relacionado às alterações climáticas cotidianas, sendo aquele da "meteorologia, por exemplo, se está fazendo frio ou calor, o clima, tempo ligado a clima" e o tempo intrínseco ao humano que é o:

"tempo vivido pelas pessoas, passado pelas pessoas, curtido, sentido, experimentado, dentro do momento que você vive. [...] é o tempo histórico, é o tempo cronológico, mas ao mesmo tempo, não é aquela coisa fria, cronologicamente falando, é a sua vivência dentro deste tempo cronológico" (Apêndice B, v. 2, p.425).

Antígona, ao separar o tempo da natureza do tempo vivido pelas pessoas se afasta da dimensão que Braudel (1978) dá à natureza como fator externo que coloca limites à ação dos seres humanos, mas que, de forma dinâmica, também contém fátores não-limitantes, o que os coloca em relação e na inter-relação, que para serem captados em sua unidade necessitam do trabalho com a longa duração a fim de que as transformações quase imperceptiveis apareçam entre fissuras de mudanças lentas.

Mas qual é a restrição dos Annales em relação à cronologia? o que se argumenta é que a precisão ordenada através da datação não oferece suficiência para a análise do processo histórico, pois na História não há a mágica da exatidão ao encerrar em si a contradição, sendo que se o "tempo verdadeiro é, por natureza, um continuum. É também perpétua mudança” (BLOCH, 2001, p.55) 
Para Braudel (1978) a cronologia é situada como aquela que serve ao: "trabalho histórico [que] decompõe o tempo decorrido, escolhe entre suas realidades cronológicas, segundo preferências e opções exclusivas mais ou menos conscientes. A história tradicional, atenta ao tempo breve, ao indivíduo, ao evento, habituou-nos há muito tempo à sua narrativa precipitada, dramática e de fôlego curto. [...] Hoje há assim, ao lado do relato (ou do 'recitativo' tradicional), um recitativo da conjuntura que põe em questão o passado por largas fatias: dez, vinte ou cinquienta anos. [...] além desse segundo recitativo, situa-se uma história de respiração mais contida ainda, e, desta vez, de amplitude secular: a história de longa, e mesmo, de longuíssima duração" (p.44).

Antígona não se afasta totalmente dos princípios colocados por Braudel (1978), mas em seu discurso há tentativas de redução do tempo histórico ao cronológico, o que constatamos em atividade do v. 2 que faz parte da apostila (Apêndice I, p. 626), utilizada na escola, onde é solicitada a comparação entre o cotidiano da criança atual com o da criança indígena de séculos passados. Em relação à compreensão do tempo pela criança ela relaciona este exercício às "atividades dele en casa, como ele usa o tempo dele, como agente criador de fatos" (Apêndice B, v. 2, p.439), demonstrando que ainda não tem a clareza sobre a intenção da atividade no que se refere à abordagem das diferenças culturais e em diferentes tempos e nem desprendimento (ainda que parcial) da questão cronológica.

Antígona entende que tempo e história se complementam e que o tempo é necessário para a explicação histórica, mas a ênfase que dá à cronologia na concepção do tempo histórico nos impele à busca de outras colocações como segue no diálogo abaixo:

Para melhor esclarecer o entendimento de sua linha de raciocínio perguntamos: lint: Você acha que a cronologia permite a compreensão do tempo do processo histórico?

Antígona: Eu acho que, não sei se eu entendi, mas eu digo, eu acho assim: quando as pessoas se voltam muito para a data, né? De repente você tem que saber usar pra que ela não... cubra os fatos, a realidade dos fatos como eles realmente aconteceram. Às vezes as pessoas ficam mais presas à questão da data do que os fatos realmente.

Ent: Se a gente tira a cronologia, então não haverá um comprometimento à compreensão do processo histórico ou haverá? 
Antígona: Bom, pra mim você viu que há, né? Porque eu estou sempre voltada à data, mas é perigoso, eu acho que a gente tem que dosar isso.

Ent: Então é possível trabalhar a História sem o uso da cronologia ou não? Antígona: Eu acho que não.

Antígona não entende a cronologia como forma de controle e não prescinde dela e nem do cuidado que se deve ter em sua utilização. Mesmo com a ausência de referências ela entende a cronologia como fundamental para a compreensão histórica e a atrela à história acontecimental (événementielle), construída em narrativa de estrutura cronológica ascendente.

Em sua ação docente se preocupa com a apropriação pelas crianças de conhecimentos sobre a cronologia, ainda que não tenha clareza da especificidade e dificuldade da compreensão temporal pela criança, reconhece que esta construção do conhecimento é permeada por tentativas, erros e acertos. Em suas estratégias metodológicas mantém a preocupação com a cronologia ao considerar a necessidade da 'organização temporal' e tem como as demais professoras o entendimento de que a 'história de vida' e a 'linha do tempo' são atividades necessárias.

\section{Conclusão}

O conhecimento construído pelas quatro professoras com as quais dialogamos, expressam certo distanciamento das mudanças que ocorreram na produção historiográfica e da crítica sobre os saberes ensinados e aprendidos na escola, concretizando distanciamento entre produções teóricas e possiveis aplicações ao campo do conhecimento escolar como resultado "da demarcação dos espaços diversificados para a atuação do profissional da História: o do pesquisador recothido ao âmbito acadêmico e o professor atuando na organização dos "saberes escolarizáveis" (MARTINS, 2002, p.49).

As quatro professoras reconhecem a continuidade histórica e colocam o presente como referência para a 'volta ao passado' como se fosse possível este retorno de forma mecânica. Na crítica à História tradicional e ao uso da cronologia de forma linear com valorização da datação, as professoras demonstram o processo de reelaboração que acontece em meio a nebulosidades com relação à História, pois nela ainda há a permanência de elementos do tempo linear, de personagens 
Salvacionistas, portanto, individualista, e a valorização de acontecimentos pontuais confundidos com o fato histórico.

Estando as mudanças atreladas às necessidades e movimentos de seu tempo, constatamos que, mesmo iniciando se a partir da década de 30, as desestabilizações para a mudança historiográfica provocadas pelo movimento denominado Les Annales não repercutiram, efetivamente, até a década de 80, sobre o cotidiano dos estudantes brasileiros.

Enfim, o tempo histórico que expressam contém pequenas aproximações com as propostas dos "Les Annales" com a permanência da compreensão da cronologia como linear; do passado como depósito de precedentes e o futuro na perspectiva do progresso como horizonte de mudanças, nos indicando que as mudanças propostas para a História estão em processo de construção, na provocação de desestabilizações perante o sistema mental constituído e consolidado em relação ao tempo histórico tradicional.

\section{Referências}

BLOCH, Marc. L. B. Apologia da história ou o ofício de historiador. Rio de Janeiro: Jorge Zahar Ed., 2001.

BRAUIDEL, Fernand. Escritos sobre a história. São Paulo: Perspectiva, 1978. (Coleção Debates).

CERTEAU, Michel de. A história: uma paixão nova. In: LE GOFE, Jacques et al. $\mathbb{A}$ nova história. São Paulo: Edições 70, 1977.

CHARTIIR, Roger. A história culturral: entre práticas e representações. Rio de Janeiro: DIFEL, 1990.

ELIAS, Norbert. Sobre o tempo. Rio de Janeiro: Jorge Zahar Ed., 1998.

A sociedade dos indivíduos. Rio de Janeiro: Jorge Zahar Ed., 1994.

LAHIRE, Bernard. Homem plural: os determinantes da ação. Petrópolis: Vozes, 2002.

LÉVI-STRAUSS, Claude. O pensamento selvagem. Campinas: Papirus, 1989.

MARTINS, Maria do Carmo. A história prescrita e disciplinada nos curréculos escolares: quem legitima esses saberes? Bragança Paulista: EDUSF, 2002.

PEARCE, W. Barnett. Novos modelos e metáforas comunicacionais: a passagem da teoria 
à prática, do objetivismo ao construcionismo social e da representação à reflexibilidade. In: SCHNITMAN, Dord Fried. Novos paradigmas, cultura e subjetividade. Porto Alegre: Artes Médicas, 1996.

PEL.BART, Peter Pál. O tempo não-reconciliado: imagens de tempo em Deleuze. São Paulo: Perspectivas, 2004. (Coleção Estudos).

REIS, José Carlos. Temapo, história e evasão. Campinas: Papirus, 1994.

RÜSEN, Jöm. RRazão histórica: teoria da história: os fundamentos da ciência histórica. Brasília: UNB, 2001.

\section{Historical Time and Chronology: the known versus the taught by elementary school teachers}

ABSTRACT

By expressing the pluralism of the historical time and the social-cultural context of its construction, and by seeing chronology as representative of its own time and space, this study tried to recognize in the discourse and pedagogical actions of four (4) fourth grade Elementary School teachers, their assumptions about the recent changes in historiography, specifically in regards to chronology. The alternatives used by the teachers to meet the needs of their students due to their heterogeneity were analyzed, taking into consideration the impact of their education on these options/alternatives and justifications for the teaching of History. Using as reference the theoretical assumptions from the "Les Annales " movement, the research used two semi-directive interviews, observation of school facilities, the lessons plus the collection and analysis of the textbooks and students' notebooks, school curriculum, and programs from University History Course disciplines. Listed among the theoretical references used in this study are the following authors: Piaget, Vygotsky, M.Bloch, L.Febvre, Furet, Certeau, Le Goff, Nora, Rüisen and Kosseleck.

Key-words: History teaching - Teacher development - Historical time Chronology. 